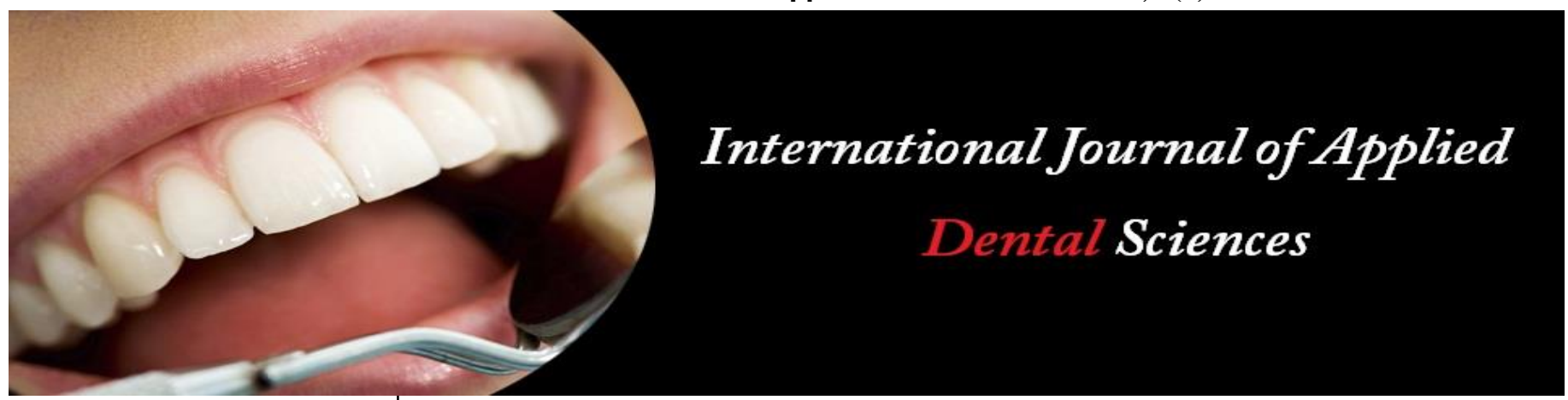

ISSN Print: 2394-7489

ISSN Online: 2394-7497

IJADS 2021; 7(3): 289-291

(C) 2021 IJADS

www.oraljournal.com

Received: 01-05-2021

Accepted: 08-06-2021

\section{Dr. Samreen Zeya}

Intern Student, Department of

Public Health Dentistry, Darshan

Dental College \& Hospital, Udaipur

Rajasthan, India

\section{Dr. Jaya Bharti Sharma}

Intern Student, Department of

Public Health Dentistry, Darshan

Dental College \& Hospital, Udaipur

Rajasthan, India

\section{Dr. Pulkit Chaturvedi}

Associate Professor, Department of Public Health Dentistry, Darshan

Dental College \& Hospital, Udaipur

Rajasthan, India

\section{Dr. Astha Doshi}

Senior lecturer, Department of

Public Health Dentistry, Darshan

Dental College \& Hospital, Udaipur

Rajasthan, India

Dr. Saloni Mathur

Intern Student, Department of

Public Health Dentistry, Darshan

Dental College \& Hospital, Udaipur

Rajasthan, India

\section{Dr. Nirvani Shah}

Intern Student, Department of

Public Health Dentistry, Darshan

Dental College \& Hospital, Udaipur

Rajasthan, India

\section{Dr. Kajal Asnani}

Intern Student, Department of

Public Health Dentistry, Darshan

Dental College \& Hospital, Udaipur

Rajasthan, India

\section{Dr. Komal Ozha}

Intern Student, Department of

Public Health Dentistry, Darshan

Dental College \& Hospital, Udaipur

Rajasthan, India

\section{Corresponding Author:}

\section{Dr. Pulkit Chaturvedi}

Associate Professor, Department of

Public Health Dentistry, Darshan

Dental College \& Hospital, Udaipur

Rajasthan, India

\section{Dental quacks: Liars to the society}

\author{
Dr. Samreen Zeya, Dr. Jaya Bharti Sharma, Dr. Pulkit Chaturvedi, Dr. \\ Astha Doshi, Dr. Saloni Mathur, Dr. Nirvani Shah, Dr. Kajal Asnani and \\ Dr. Komal Ozha
}

\section{DOI: https://doi.org/10.22271/oral.2021.v7.i3e.1312}

\section{Abstract}

Dentistry has come A long way in the last one and a half century; today it is ranked as one of the most respected professions. It is incumbent upon dentists everywhere to protect this hard-earned reputation by weeding out quacks among them. Dental diseases restrict activities in school, work and home and often significantly diminishes the quality of life for many children and adults, especially those who have low income or are uninsured. Quackery in dentistry has been a problem for decades. There are a large number of quacks practicing illegal dentistry in India, pretending to have skill, knowledge or qualification which they do not actually possess. It arises when there are inadequate numbers of competent and trained practitioners or when their charges appear prohibitive to a segment of the population. Poorly educated people often become gullible prey to quacks who perform dental treatment, which is often harmful to patients. It's a time to take measures to stop such unethical practices.

Keywords: Dental quackery, malpractices, dental diseases

\section{Introduction}

Dentistry is one of the most respected profession and has progressed tremendously in the last century, but it still faces serious problems regarding accessibility. A large part of the world's population is devoid of affordable, safe and proper oral care. In high income countries, disadvantaged communities face access barriers which have a high impact on their oral health status. In low- and middle-income countries, a large segment of people residing in rural areas, and belonging to low-economic strata, suffer from inaccessibility to formal oral health care. In such situations, illegal oral health care providers take advantages in oral health care services [1].

The illegal provision of oral care, dental quackery (DQ) can be harmful physically, emotionally, psychologically and financially, because of either the treatment itself or inaccessibility to adequate treatment that might be helpful ${ }^{[2]}$.

Despite having more than 300 registered dental colleges and a large number of government and private organizations providing dental care, there is massive shortage of trained dental professional especially in rural areas owing to mismatch in the distribution of manpower. As against the dentist to population ratio of 1:10,000 in urban area, the ratio is 1:2.5 lac in rural area ${ }^{[3]}$ has led the dental quacks to have flourishing business especially in rural and semiurban areas ${ }^{[4]}$.

Quackery has been defined as, "the fraudulent misrepresentation of one's ability and experience in the diagnosis and treatment of disease or of the effects to be achieved by the treatment offered ${ }^{[5]}$. According to one of the published reports, there are about 2,500-3,000 quacks practicing illegal dentistry in the capital of India alone, pretending to have skill, knowledge or qualification which they do not actually possess ${ }^{[6]}$.

There is a paucity of scientific literature addressing this problem and the magnitude of the issue is unknown. In the context of betterment of the situation, the problem of dental quackery merits closer attention and genuine efforts to tackle it. 
Table 1: Commonly performed malpractices by dental quacks and their associated risks

\begin{tabular}{|c|c|}
\hline Malpractices & Risks \\
\hline 1. Suction discs for denture retention. & Erosion of palatal mucosa. \\
\hline 2. Use of screw drivers and pliers for extraction of teeth. & $\begin{array}{c}\text { Displacement of remnants into other anatomical spaces. } \\
\text { Infection. }\end{array}$ \\
\hline 3. Replacement of missing tooth using extracted tooth. & Foreign body reaction. Infection. \\
\hline 4. Performing dental procedures without sterilizing instruments. & Risk of transmission of various diseases. \\
\hline 5. Fixing a tooth in edentulous area with the help of ring plating on the adjacent tooth. & Erosion of teeth. Sensitivity/pain. \\
\hline 6. Use of hydrogen peroxide for stain removal and whitening of the teeth. & Tooth loss. Underlined bone loss. \\
\hline 7. Restoration using self-curing acrylic as restorative material. & Risk of transmission of various diseases. \\
\hline 8. Use of wires for stabilization of tooth or denture with the support of adjacent teeth.
\end{tabular}

1. Suction disc, which provide high retention, are not recommended anymore because of destructive effect of negative pressure on palatal tissues and can cause perforations and erosion in the palate (Fig. 1).

2. Usage of screw drivers and pliers for extraction can injure the surrounding areas of tooth and oral cavity. It increases chances of bone fracture (Fig. 2).

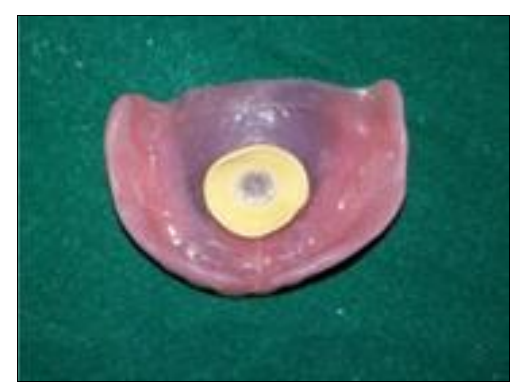

Fig 1: Show the Suction discs for denture retention.

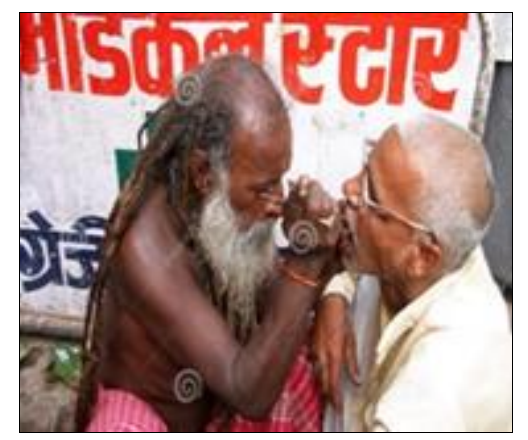

Fig 2: Use of screw drivers and pliers for extraction of teeth.

3. Several quacks use extracted tooth for the replacement of missing tooth that causes foreign body reaction and infections.

4. Use of unsterilized instruments for performing dental procedures can transmit various diseases from one person to other, this can lead to the spread of infection (Fig. 3).

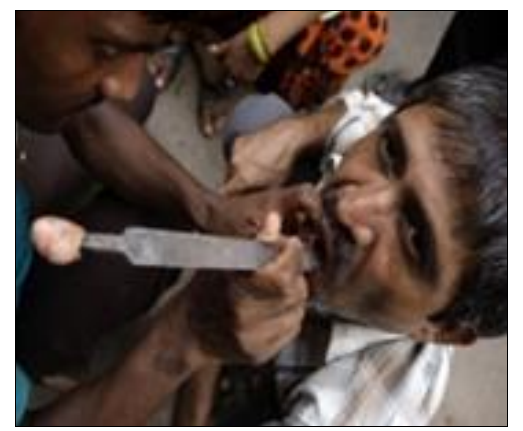

Fig 3: Replacement of missing tooth using extracted tooth.

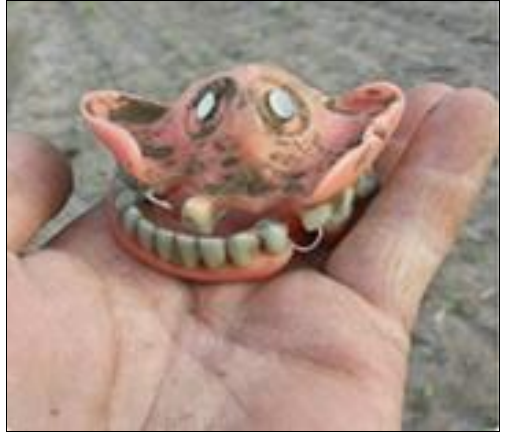

Fig 4: Performing dental procedures without sterilizing instruments.

5. Malpractices like fixing the tooth in the edentulous area using the ring plating on the adjacent tooth produces, abnormal forces to the adjacent tooth leading to loss of tooth structure or even fracture in most of the cases (Fig. 4).

6. Hydrogen peroxide which is very harmful if not used judiciously can harm the tooth and surrounding areas, so the use of it without the protocol as by dental quacks can even erode the tooth structure and damage the surrounding areas.

7. Majority of quacks practice restoration with self-curing acrylic that can injure dental pulp and predispose to various dental problems (Fig. 5)

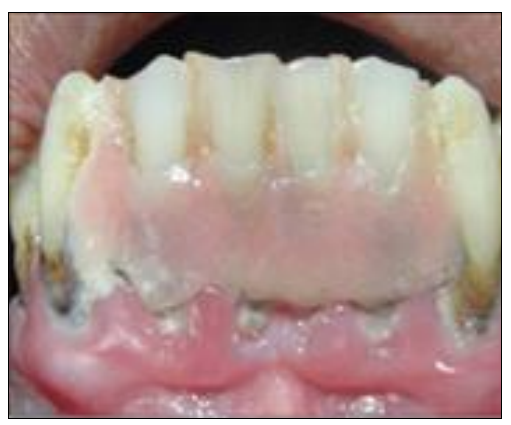

Fig 5: Fixing a tooth in edentulous area with the help of ring plating on the adjacent tooth.

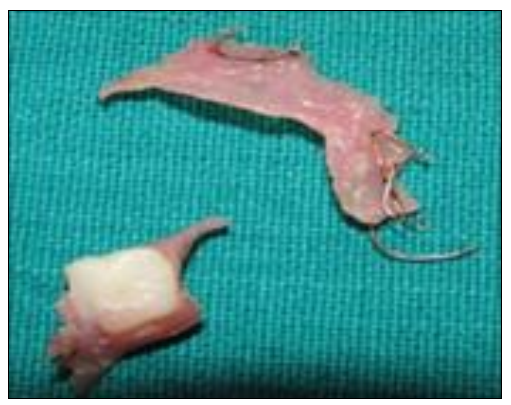

Fig 6: Use of hydrogen peroxide for stain removal and whitening of the teeth. 
8. Fixing the tooth and denture with wires by taking support of adjacent teeth can lead to loss of the teeth by producing uneven and abnormal forces.

9. Due to the lack of awareness and money quacks are seen using a single anesthetic needle on multiple patients can transmit various diseases like AIDs, Hepatitis B, etc. (Fig. 7)

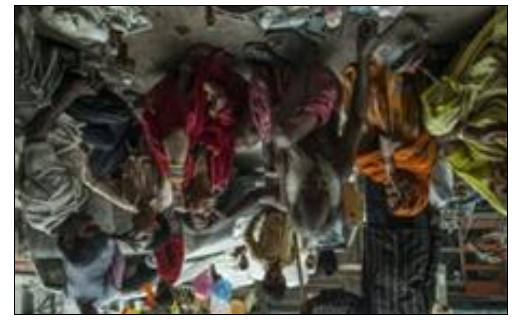

Fig 7: Restoration using self-curing acrylic as restorative material.

\section{Reasons for quackery}

It is very important to find out the reasons behind the quackery in dentistry to safeguard the health of the individuals and reasons are as follows ${ }^{[7]}$ :

Lower-and middle-class individuals, who are socioeconomically weak, find it very difficult and almost impossible to afford the dental treatment charges by a good dentist. Dental treatment requires multiple visits and patients due to unbearable pain get their treatment done from quacks as they find difficult to afford charges. Even affordable and educated patients visit quacks just to save some money. Unbearable pain to poor individuals forces them to take the services of a quack to get rid of it at very low and affordable cost. Less number of qualified dentists are available in rural places and many dentists do not want to practice in villages. The treatment charges of the qualified dentist are too high and difficult to afford by all, who are in need of oral health. While working with a qualified dental surgeon, quacks learn many dental procedures without proper instrumentation. There is lack of government policies for dental treatment to provide quality treatment through qualified dental surgeons at a very affordable cost.

Parlani S. et al. noticed that reasons for visiting a dental quack are lack of awareness followed by economy and other factors ${ }^{[8]}$.

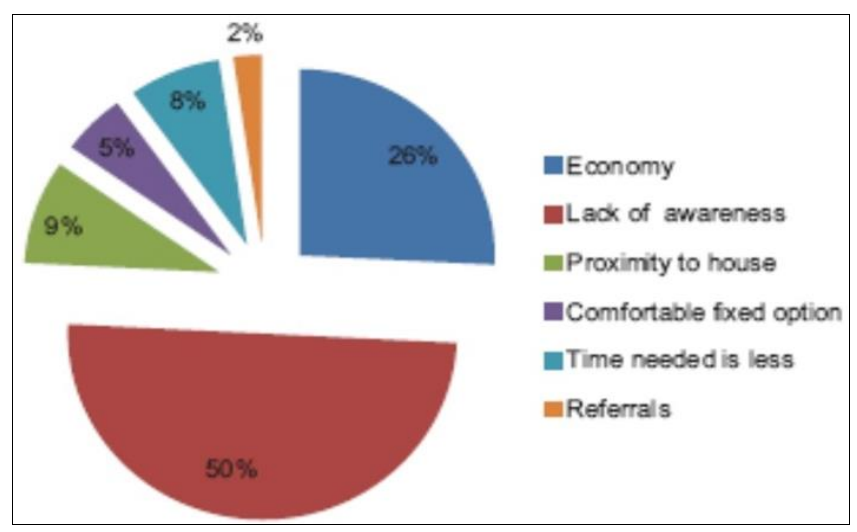

Fig 8: Reasons for visiting a quack

\section{Conclusion}

According to Chapter v, Section 49 of the Dentists Act of 1948 in India all dentists, dental hygienists, dental mechanics, need to be licensed. Therefore, these quacks can be penalized under this Act which may lead to imprisonment and penalty. ${ }^{4}$ However, the best way to tackle this menace is to provide affordable and accessible treatment option to the rural population, in particular. ${ }^{9,10 \mathrm{~A}}$ patient should only visit a qualified dentist having certificates and should not hesitate in asking for these certificates from a doctor and if the treatment is done from an unqualified person can lead to long term complications and sometimes life threatening and fatal outcomes. Despite an increase in the number of dentists over years, the count of dental quacks practicing the dental treatment has also been on the rise. Even some dentists promote dental quacks by visiting them and performing dental procedures. It is thus the duty of every dental surgeon in the country to protect the reputation of our prestigious profession being tarnished by the unqualified unauthorized dental quacks. An urgent need to address this thriving issue is not only that it hampers the work, livelihood and credentials of the dentists but can also severely affect the health of the patient due to their nescience and unethical means of practice. In many states, the state administration along with the state dental council are trying their best and have sealed some illegal establishments run by quacks. Indeed, a double-edged sword that is reaping our society and only- "A stitch in time can save nine."

\section{References}

1. Benzian H, Jean J, Van Palenstein Helderman W. Illegal oral care: more than a legal issue. Int Dent $\mathbf{J}$ 2010;60:399-406.

2. Chalakkal P, Ataide Ide N, Krishnan R, Pavaskar R. Dental treatment abuse. J Clin Diagn Res 2014;8:ZD01ZD02.

3. Lal S, Paul D, Vashisht B. National oral health care programme (NOHCP) implementation stratagies. Indian J Community Med 2004;29:3-10.

4. Bhushan P, Kumar K, Ali FM, Nandkeoliar T. Menance of quack in dentistry: A case report. IOSR JDMS 2016;15;115-8.S

5. Dorland WAN. Dorland's Illustrated Medical Dictionary. 32nd ed. Philadelphia: Saunders 2011.

6. India Today. No efforts to curb growing numbers of illegal doctors in Delhi. Available at https://www.indiatoday.in/india/north/story/quacks-indelhi-illegal-clinics-in-delhi-ima-arvind-kejriwalgovernment-delhi-high-court-184847-2014-03-14 (accessed January 2019.)

7. Kumari S, Mishra SK, Mishra P. Am evidence-based review on quackery in dentistry. BLDE Univ J Health Sci 2018;3:75-8.

8. Parlani S, Tripathi S, Bhoyar A. A cross-sectional study to explore the reasons to visit a quack for prosthodontic solutions. J Indian Prosthodont Soc 2018;18:231-8.

9. Oumeish OY. The philosophical, cultural, and historical aspects of complementary, alternative, unconventional, and integrative medicine in the old world. Arch Dermatol 1998;134:1373-86.

10. Pauly NG, Warrier S, Kashyap RR, Rao PK, Kini R, Bhandarkar GP. The curse of quackery in dentistry; a double edged sword. Arch Med Health Sci 2017;5:92-4. 